\title{
Apetitos de Góngora y Lezama
}

Lezama invoca con frecuencia a Góngora en sus ensayos, y en Paradiso Góngora es una de las figuras que los personajes mencionan con insistencia en sus discusiones literarias. Lezama ha dedicado además un largo y espeso ensayo, "Sierpe de don Luis de Góngora," a la obra del cordobés, y otro, "La curiosidad barroca," al período en que se inscribe su obra.' La crítica, por su parte, no ha perdido la oportunidad de proclamar a Lezama barroco, ni ha dejado de acudir a Góngora como punto de referencia al enfrentarse a las ya proverbiales dificultades de la escritura lezamiana. Se ha tratado casi siempre de gestos rituales, ya que desde los simbolistas, toda poesía difícil ha sido comparada con la de Góngora; en la mayoria de los casos, como en el de Neruda, para suscitar más confusiones que aclaraciones. Pero el caso de Lezama parece ser distinto, y el gesto ritual se justifica tal vez por la insistencia con que el escritor cubano se refiere a Góngora, analiza su poesía, especula sobre su vida privada, medita sobre el impacto de su poesía en Hispanoamérica, menciona los comentarios que su obra ha suscitado en distintas épocas. Quien lea a Lezama no podrá dejar de notar que Góngora es una figura clave en su obra, ni podrá eludir la sospecha de que su poética está de alguna manera vinculada a la del cordobés.

Lezama deja en sus ensayos numerosas huellas que permiten reconstruir la historia de su interés por el barroco y por Góngora en particular. En la página inicial de "La curiosidad barroca" recuerda cómo, después de haber sido anatema en el siglo pasado, el barroco ha sido utilizado en el nuestro para designar fenómenos tan disímiles en apariencia como la pintura de Rembrandt y las matemáticas de Leibnitz, y, dice Lezama con sorna, " "hasta algún crítico excediéndose en la generalización, afirmaba que la tierra era clásica y el mar barroco.’’ 2 Lo que quiere destacar Lezama con su broma, que va sin duda dirigida a Eugenio D'Ors, es que el barroco se ha convertido en panacea en este siglo. Pero es en esa panacea donde se hace comprensible su obra, y su interpretación de Góngora, según veremos.

1 .'Sierpe de don Luis de Góngora," Orbita de Lezama Lima. Ensayo preliminar, selección y notas de Armando Alvarez Bravo (La Habana: Ediciones Unión, 1966), pp. 256-90; “La curiosidad barroca," La expresión americana (Madrid: Alianza, 1969), pp. 43-82.

2 "La curiosidad barroca,", op. cit., p. 46. 
En términos generales, la popularidad del barroco en el siglo XX se remonta a las vanguardias (específicamente al expresionismo alemán, como ha señalado Wellek), que encontraban en toda desmesura o aparente incoherencia un deleite que oponer al tranquilo realismo burgués del siglo anterior. ${ }^{3}$ Pero podemos con mayor precisión aludir a un auge del barroco en el mundo hispano que comienza en los años veinte, no sólo en la literatura de creación, sino también en la crítica. No hay más que tomar nota de las referencias de Lezama en sus ensayos para percatarse de que fue asiduo lector de la Revista de Occidente, y de las ediciones hechas por el equipo de la Revista; hablo no sólo de las alusiones a Ortega mismo, sino también a Spengler, a Scheler, a Hegel, a Worringer. Fue sin duda en la Revista de Occidente donde Lezama primero leyó a algunos de los más conocidos exégetas del barroco (casi todos alemanes): a Wölfflin, a Eugenio D'Ors, a Worringer y a Spengler. Todos estos críticos y pensadores, que fueron promovidos activamente por Ortega a través de la Revista de Occidente, tuvieron un impacto extraordinario sobre la vanguardia hispanoamericana, y sobre la cubana en particular. ${ }^{4}$ Desde luego, no podría dejar de mencionarse, como fenómeno paralelo a la generación española del ' 27 que, como es sabido, resucitó a Góngora en el tercer centenario de su muerte, y de la que surge su más asiduo y brillante exégeta, Dámaso Alonso. Y en ese mismo contexto habría que añadir un elemento que ha recibido relativamente poca atención: la popularidad del barroco entre los escritores hispanoamericanos contemporáneos de diversas edades (conocida es, por supuesto, la afinidad que algunos modernistas, Darío, Martí, sintieron por la poesía barroca). Borges, por ejemplo, dedica elogiosas páginas a Quevedo, y un poema a Gracián, amén de la presencia de Cervantes en toda su obra. Alejo Carpentier se declara barroco, menciona repetidas veces en sus ensayos la picaresca española, y cita a menudo a Lope. Carlos Fuentes cita varias veces a Calderón en La muerte de Artemio Cruz, y en Aura, la joven protagonista se trueca en la anciana consuelo en brazos de su amante, escena que recuerda aquélla de El mágico prodigioso de Calderón en que Justina se convierte en cadáver en brazos de Cipriano. Octavio Paz, en Salamandra, escribe todo un poema que es una glosa del célebre soneto de Quevedo "Amor constante más allá de la muerte." E1 propio Lezama, en "La curiosidad barroca," propone que el barroco es el primer movimiento artístico americano, y su estudio entronca con la tradición historiográfica iniciada en los años cuarenta por Pedro Henriquez Ureña y Mariano Picón Salas. En la actualidad, Severo Sarduy intenta lanzar un puente teórico entre el barroco y la modernidad por las afinidades en la cosmología de ambas épocas.

Cuando en la página antes mencionada de "La curiosidad barroca" Lezama menciona las matemáticas de Leibnitz, lo hace sin duda recordando a Spengler. Para Spengler, uno de los primeros pensadores en desarrollar una teoría global sobre el barroco en este siglo, " $\mathrm{El}$ siglo clásico de esta matemática barroca [...] es el siglo XVIII, que empieza con los

3 "I would be hesitant to dogmatize about the exact reasons for this revival of German baroque poetry; part of it may be due to Spengler, who had used the term vaguely in The Decline of the West, and part is due, I think, to a misunderstanding. Baroque poetry was felt to be similar to the most recent German expressionism, to its turbulent, tense, torn diction..." Concepts of Criticism, ed. Stephen G. Nichols, Jr. (New Haven: Yale University Press, 1964), p. 76.

4 Para más detalles sobre este punto ver mi "Isla a su vuelo fugitiva: Carpentier y el realismo mágico," Revista Iberoamericana, 40 (1974), pp. 9-64. En Las eras imaginarias (Madrid: Editorial Fundamentos, 1971), Lezama refuta el historicismo representado sobre todo por los filósofos mencionados. 
descubrimientos decisivos de Newton y Leibnitz y sigue con Euler, Lagrange, Laplace, hasta llegar a Gauss.',5 Y es que Spengler establecía una distinción radical entre las matemáticas griegas, o clásicas, que funcionaban a base de números que representaban entidades concretas, y las matemáticas occidentales o fáusticas, que se lanzan al infinito por números-verdaderas metáforas-que representan relaciones abstractas: "Para el espíritu antiguo no hay más que un número entre el 1 y el 3 ; para el espiritu occidental, hay una colección infinita." 6 La distinción entre estos dos tipos de representación en Spengler nos permite explicar una afirmación en principio sorprendente que Lezama hace sobre Góngora :

La luz de Góngora es un alzamiento de los objetos y un tiempo de apoderamiento de la incitación. En ese sentido se puede hablar de goticismo de su luz de alzamiento. La luz que suma el objeto y que después produce la irradiación. La luz oída, la que aparece en el acompañamiento angélico, la luz acompañada de la transparencia de los ángeles al frotarse las alas. Los objetos en Góngora son alzados en proporción al rayo de apoderamiento que reciben. Solamente que ese rayo y alzamiento se ven obligados a viscicitudes renacentistas. El furor de ese rayo metafórico son de impulsión gótica, apagado por un reconocimiento en fabulario y usanzas grecolatinas. ${ }^{7}$

En La decadencia de Occidente, Spengler había dicho que "El gótico, y el barroco son la juventud y la vejez de un mismo plantel de formas, ${ }^{, 8}$ ya que para él, el gótico es la primera manifestación estilística del alma fáustica lanzada hacia el infinito (por oposición al alma antigua, de proyección concreta). Pero la fuente común de Spengler y Lezama es aquí Wilhelm Worringer, a quien Lezama sigue punto por punto en la cita anterior, y en gran parte del ensayo sobre Góngora.

Worringer distinguia cuatro manifestaciones del arte: el arte del hombre primitivo, que según él es pura abstracción, la imposición de un orden para enfrentarse al terror de lo desconocido, del mundo que se presenta como peligro: el arte clásico, que representa la satisfacción en el conocimiento, y por lo tanto la plácida aceptación de la realidad y sus formas; el arte oriental, que es un abandono al no-conocimiento y a la sensualidad; y el gótico. El gótico es el punto intermedio entre el arte primitivo y el arte clásico: "Y asi-dice Worringer en Form-probleme der Gotik (1912)-el dualismo [del hombre: primitivo que teme al cosmos], que ya no es lo suficientemente fuerte como para negar la: vida, que ya ha sido debilitado por un conocimiento que no obstante le niega aún la completa emancipación, se resuelve en una confusa manía de éxtasis, un ansia convulsiva por fundirse en un rapto supra-sensible, en un pathos cuya esencia especifica es la falta de

5 La decadencia de Occidente, tr. Manuel Garcia Morente (Madrid: Espasa Calpe, 1966 [1923]), I, 117.

6 Ibid., p. 116.

7 "'Sierpe de don Luis de Góngora," op. cit., p. 258.

8 Spengler, p. 267. 
mesura.", 9 Es decir, el gótico se debate entre la imposición de una linearidad abstracta, ascendente y trascendente, y la presencia y fuerza de las formas de lo real y sensual. Para Worringer, como después para Lezama, el arte del Renacimiento, con su carga de humanismo clasicista, atenúa momentáneamente el trascendentalismo retorcido del gótico, pero éste renace en el barroco, que es el arte del anti-humanismo, trascendente una vez más, que aspira a un gozo de lo eterno en las convulsiones del éxtasis. Anhelo de trascendencia y presencia de lo sensual: estos dos elementos que Worringer aisla como los componentes de una dialéctica gótica nunca resuelta en síntesis, son las bases sobre las cuales Lezama desarrolla su ensayo, " Sierpe de don Luis de Góngora.",

Toda esta historia reverbera en Lezama, tanto en sus ensayos como en sus poemas y en Paradiso. No podemos prescindir de ella, a riesgo de otorgar una falsa originalidad a sus postulados. $\mathrm{Y}$, sin embargo, tampoco podemos agotar con esa historia la lectura que Lezama hace de Góngora. Lezama no es un manso seguidor de modas literarias o filosóficas; por el contrario, si algo tiene su obra, en cualquier género, es que rompe con todo hábito literario, y desafía las mejores y más tenaces tentativas de exégesis académica. Góngora, evidentemente, forma parte de un contexto dado, de toda una estética vanguardista que lo convierte en paladín de la poesía pura y hermética. Pero el papel que desempeña en la obra de Lezama es todavía más complejo y rico en sugerencias. La lectura que Lezama hace de Góngora es más crítica que la generalmente practicada por la vanguardia - no una simple aceptación de la poética del cordobés, sino una amorosa exégesis que a la postre sirve a Lezama para mostrar la falla de la poesía gongorina. Es decir, el punto a partir del cual él intenta forjar otra poética.

Hay un pasaje oscuro y sugestivo en "Sierpe de don Luis de Góngora" que puede servir de vía de acceso a esta segunda lectura: "Faltaba [en Góngora] a esa penetración de luminosidad la noche oscura de San Juan, pues aquel rayo de conocer poético sin su acompañante noche oscura, sólo podrá mostrar el relámpago de la cetrera actuando sobre la escayolada. Quizás ningún pueblo haya tenido el planteamiento de su poesía tan concentrado en ese momento español en que el rayo metafórico de Góngora, necesita y clama, mostrando dolorosa incompletez, aquella noche oscura envolvente y luminosa. "' 10 ¿Qué quiere decir Lezama al hablar de " dolorosa incompletez"? ¿Se tratará aquí únicamente del contraste entre la fe de San Juan y el supuesto nihilismo gongorino? Es posible. Pero creo que hay, además, una intuición que tiene tanto que ver con la poesía como con la fe, aunque ésta también desempeña un papel importante en el sistema lezamiano. Para

9 El libro de Worringer aparece en 1912, bajo el título Formprobleme der Gotik; en 1907 se habia publicado un preámbulo teórico intitulado Abstraktion un Einfilung. Ortega, en el verano de 1911 , dedicó una serie de artículos a Worringer en El Imparcial, en los que resume las teorías del alemán, y años más tarde hace publicar en la Revista de Occidente, varias traducciones. Además de Lezama, Carpentier se refiere a Worringer en varias ocasiones en su columna "Letra y Solfa", publicada durante los años cincuenta en El Nacional de Caracas; en "El acoso,"' el joven estudiante de arquitectura piensa en un libro que debe ser Formprobleme der Gotik: "¿Por qué no tenían los hombres de hoy aquella antigua providencia de 'acogerse a sagrado,' de que se hablaba en un libro sobre el Gótico?" Cito por Guerra del tiempo (México: Compañía General de Ediciones, 1966), p. 250. Severo Sarduy me ha indicado que todavía en los anos cincuenta, el grupo de escritores que colaboraba en Ciclón hablaba de "simpatía y abstracción." Agradezco a mi colega de Cornell, Urbain De Winter, algunas sugerencias iniciales sobre Worringer. Cito aqui por Form in Gotbic, tr. Sir Herbert Read (Nueva York: Schocken Books, 1969), pp. 68,79 .

io. "'Sierpe de don Luis de Góngora," op. cit. , p. 271. 
comprender lo que sugiere Lezama en ese pasaje se impone hacer un rápido recorrido por la poesía renacentista.

En la poesía de Góngora, evidentemente, culmina un proceso que tiene su origen más inmediato en Petrarca: El petrarquismo surge de impulsos contradictorios que van creando una fisura cada vez más ancha a medida que avanza el Renacimiento. Petrarca deriva un nuevo lenguaje poético a base de elementos que tiene a su alcance-la tradición provenzal que le llega por el dolce stil nuovo, el legado clásico-pero que no son fácilmente armonizables. Por un lado su clasicismo lo lleva a acuñar un lenguaje poético vernáculo que aspira a la perfección atribuida a la poesía latina. Por esa vertiente Petrarca va hacia una codificación cerrada de la poesía. Por otra, Petrarca busca centrar ese lenguaje en una presencia concreta-en un aquí y ahora que es la individualidad de un yo lírico manifestándose a través de ese lenguaje. La perfección formal que apetece Petrarca conspira contra la innovación, que puede crear la desarmonía, pero que es la diferencia mediante la cual la presencia centralizadora de ese yo lírico puede llegar a revelarse. Hoy se puede comprobar que Petrarca, a pesar de sus testimonios en contra, pulió con esmero y hasta con neurastenia flaubertiana sus Rimas; y que, como Juan Ramón Jiménez, nunca se sentía satisfecho ante la última de las muchas (y potencialmente infinitas) versiones de sus poemas. Es perceptible hoy al leer su poesía la tensión hacia fines sólo armonizables en el más elevado plano de abstracción conceptual: el ansia de perfección formal de estirpe platónica y clásica, y el amor insatisfecho, que en sus más altos vuelos, también alcanza alturas neo-platónicas. La fusión entre el yo lírico y el código a través del cual se expresa es sólo posible a ese nivel de abstracción.

En los epígonos de Petrarca en el siglo XVI, el lenguaje cada vez más perfecto llega a convertirse en un código autónomo que significa cada vez menos, que ese código, libre ya de toda traba centralizadora, se entrega a sus propios giros. Podemos, en efecto, hacer el experimento de tomar un soneto de Petrarca sobre un tema dado y agrupar a su alrededor en un mismo plano sonetos de Garcilaso, Ronsard, Spencer y Quevedo, que no parecen sino glosas del "original," variaciones y juegos. En Herrera, como es sabido, ya hay un esfuerzo consciente y expresado con autoridad teórica, de forjar una lengua poética autónoma. Su contemporáneo, Fray Luis, que sin duda tomó conciencia del problema, apeló a una fórmula filosófico-teológica de anclar ese lenguaje, y afirma lo siguiente en $D e$ los nombres de Cristo: "La [poesia] inspiró Dios en los ánimos de los hombres para con el movimiento y el spíritu della levantarlos al cielo, de donde ella procede; porque poesía no es sino una comunicación del aliento celestial y divino." 11 Como la música de Francisco Salinas, la perfección del lenguaje poético procede del cielo, y forma parte de la armonía cósmica-de la música de las esferas. La música verbal del poema emana del aliento de Dios, no de la voz del poeta. Fray Luis tiene que suponer una fuerza externa que cifra sus poemas, anulando su propia presencia, y su propia voz como elemento centralizador. De ahí el tono "frío" que con frecuencia se ha atribuido a sus poemas.

El proceso que comienza con Petrarca es de desarraigo del lenguaje poético. Ante la perfección cada vez mayor de la poesía, del vernáculo domado a las exigencias del nuevo clasicismo, la voz lírica queda anulada, no se reconoce ya en el liso cristal de su propia

11 De los nombres de Cristo ed. y notas. Federico de Onís (Madrid: Clásicos Castellanos, 1956), I, 174. 
creación. El lenguaje gira en torno a si mismo y a su, aunque vasto, limitado universo alusivo, como un planeta desprendido de su órbita. Cuando llegamos al barroco, ya ese lenguaje es un lenguaje demente, alienado, que apunta a un vacio entre el poeta y el mundo, y entre el poeta y su propia creación; un lenguaje que ha perdido toda capacidad referencial, que no significa sino el abismo entre las palabras y el ser. Por ello no parece fortuito que muchas de las figuras que aparecen en la literatura eglógica del Renacimiento y el Barroco sean seres alienados, excluidos de la armónica belleza del locus amoenus que generalmente los rodea, ni que el tema de la locura tenga tanta preponderancia durante esos dos períodos. La "incompletez' de que habla Lezama con respecto a Góngora tiene que estar vinculada a este proceso, que podemos analizar brevemente en fragmentos de dos poemas señeros: el canto XXIII del Orlando furioso, y un conocido pasaje de la Egloga II de Garcilaso.

En el canto XXIII, como es sabido, Orlando encuentra, primero una multitud de mensajes de amor grabados por Angélica en la corteza de los árboles, luego una cueva donde ella y Medoro han consumado su amor. En las paredes de la gruta, Orlando encuentra un poema escrito en árabe (que Ariosto se toma el trabajo de decirnos, "así como el latín bien lo entendía"), en que Medoro canta su satisfacción (cito por la traducción de 1550 hecha por el capitán Jerónimo de Urrea):

Ledas plantas, fresca agua, yerba bella,

Cueva umbría de gran frescura ornada,

Do Angélica gentil, hija doncella

De Galafrón, de mil en vano amada,

Desnuda entre mis brazos gocé de ella,

Por la comodidad que aquí me es dada. ${ }^{12}$

Con esperanzas de que no sea cierto lo que sospecha, Orlando busca albergue y da con una choza, también cubierta toda de mensajes de amor, ya sin duda escritos por Angélica ("esta letra conozco, no lo dudo"), y alli le cuentan en hirientes detalles lo que él menos quería escuchar. Al amanecer, Orlando regresa a la cueva

Donde escribió Medoro el epigrama,

En ver su injuria escrita así presente,

Se enciende tal que en él quedó drama

que no fuese odio, rabia, ira furiosa.

La espada aquí sin más sacó famosa,

Cortó el escrito y mármol presuroso.

Hasta el cielo las rajas han subido.

Desdichada cueva y sitio umbroso

Do Angélica y Medor se vio imprimido. ${ }^{13}$

La locura de Orlando se manifiesta ante la escritura, emblemáticamente grabada, fijada, en

12 Orlando Furioso. Dirigido al Principe Don Philipe Nuestro Seffor, traducido en romance castellano por don Ieronymo de Vrrea. An se añadido breves moralidades arto necesarias a la declaración de los cantos, y la tabla es muy mas aumentada. A Lyon en Casa de Gulielmo Roville, 1550, p. 204. He modernizado la puntuación y la ortografia,

13 Ibid, p. 206. 
el mármol, que canta lo impensable, que es la plenitud amorosa, y la coincidencia de esa plenitud con la inscripción del poema-plenitud en la unión física no abarcable por el lenguaje petrarquista, y sólo posible aqui por el disloque producido por la ironia y el humor. El pasaje está lleno de sugerencias: la escritura en árabe, que distancia a Orlando de ese poema de plenitud, la saturación, la repetición interminable de mensajes, grabados en los árboles, en las paredes de la choza, en la gruta, en la fuente, como si el mundo real fuese incapaz de contener esa escritura prohibida, que es la de la saciedad. La locura de Orlando es ante el lenguaje pletórico; su agresión es contra esos signos que desbordan la realidad con mensajes que cierran la fisura, la ruptura entre lenguaje y significado. Es sólo en la locura o en el humor y la ironía que la 'incompletez" logra completarse.

En la Egloga II, emulando posiblemente a Ariosto, Garcilaso ofrece una escena de locura igualmente sugestiva ${ }^{14}$ La égloga ha suscitado algunas criticas negativas por su desmesura, desarmonía y extraña complejidad. ${ }^{15}$ La primera parte relata los infortunios de Albanio y su locura de amor por Camila; en la segunda, el mago Severo ve en una urna (especie de Aleph borgiano) toda la historia de la casa de Alba. Las dos partes de la égloga se miran como reflejos especulares: 1a historia del joven Alba será como una repetición de la de Albanio. No cabe duda, por la longitud y complejidad del poema, que fue ésta la obra más ambiciosa de Garcilaso, y a mi entender la que más claramente apunta hacia Góngora. Pero quisiera sólo destacar la escena de la locura de Albanio; escena genial en la que no vemos por cierto al Garcilaso sobrio y mesurado que la crítica alaba. Albanio se encuentra con Camila después que ésta ya lo ha rechazado, y trata de explicarse una vez más ante ella; pero Camila no lo deja y trata de escapar. Albanio la agarra por una mano, forcejean, Camila grita que Albanio le va a romper un dedo, y finalmente escapa. Albanio pierde la razón:

Descargado me siento de un gran peso;

Paréceme que vuelo, despreciando

Monte, choza, ganado, leche y queso.

¿No son aquestos pies? Con ellos ando.

Ya caigo en ello, el cuerpo se me ha ido;

Sólo el espíritu es éste que ahora mando.

$¿$ Hale hurtado alguno o escondido

Mientras mirando estaba yo otra cosa?

Una figura de color de rosa

Estaba alli durmiendo: ¿si es aquella

Mi cuerpo? No, que aquella es muy hermosa. ${ }^{16}$

El forcejeo entre Albanio y Camila, la insólita alusión a la fractura del dedo (donde no deja de haber cierta comicidad), todo este desorden no puede ser más chocante en el ambiente

14 Para un estudio detallado y erudito de las relaciones entre A riosto y Garcilaso, y en particular entre la Egloga II y el Orlando, véase: R.O. Jones, "Ariosto and Garcilaso," Bulletin of Hispanic Studies, 39 (1962), 153-67.

15 "Aparte de ese interés y de las expresiones del lenguaje vulgar tan abundantes en ella, la Egloga II ofrece un caudal de temas renacentistas utilisimo para fijar la ideologia de Garcilaso. Es cierto que las calidades poéticas de la obra no son uniformes.". Margot Arce de Vázquez, Garcilaso de la Vega. Contribución al estudio de la lirica española del siglo XVI, 2nda. ed. (Rio Piedras: Ediciones de la Universidad de Puerto Rico, 1961), p. 26.

16. Obras, edición y notas, Rafael Lapesa (Madrid: Clásicos Castellanos, 1963), p. 70. 
eglógico en que se desarrolla la acción. Recuérdese además que es también en esta égloga donde Garcilaso, al narrar el matrimonio del joven Alba, emplea el verso "ardiendo y deseando estar ya echado," que tanto irritó a Herrera, quien escribió en sus Anotaciones: "que muy ajeno es de su modestia y pureza, y que deslustró mucho la limpieza y honestidad de toda esta descripción." " 17 Y es precisamente en esta égloga donde parece haber un desdoblamiento claro en la lengua poética de Garcilaso. En un momento dado, durante un diálogo entre Albanio y Salicio, el primero le pregunta a su amigo: " ¿Para qué son magnificas palabras?/ $¿$ Quién te hizo filósofo elocuente,/Siendo pastor de ovejas y de cabras?" 18 Este distanciamiento irónico apunta a la fisura, a la ruptura en el seno del lenguaje poético que la locura de Albanio manifiesta en el interior de la égloga--égloga escindida, como se ha visto, en dos partes en que se pretende igualar una serie de sucesos históricos y contemporáneos y una ficción pastoril. La armonía es imposible, como el amor de Albanio, que lo lleva a la incoherencia, a la afasia, y por último a la locura. La cómica y grotesca separación de cuerpo y espiritu destaca la separación entre la facticidad del lenguaje y su imagen abstracta--el yo desprendido de Albanio es el que habla y nombra como fuera de sí esa carne que le han robado y desde la cual no puede expresarse (después de este episodio Albanio se queda dormido y no vuelve a hablar en el poema). El desorden de este gran poema de Garcilaso es su rasgo más revelador. La distancia entre esa carne rosada, el cuerpo de Camila que Albanio cree es ahora el suyo desasido, y el yo que la nombra, sin poderla recuperar, sin poderla asimilar, es el germen del barroco poético. De la Egloga II de Garcilaso a las Soledades, de Albanio a ese peregrino sin nombre no hay más que un paso.

Creo que se puede resumir el proceso que he venido describiendo con un brillante párrafo del libro de Leo Spitzer sobre La Dorotea de Lope:

El lenguaje bartoco no es sino un lenguaje que aprovecha la radical inconexión de todos los lenguajes con la belleza. Un lenguaje que ensancha el abismo entre el ser y la apariencia y que dora lo feo o lo malo con un nimbo de belleza. Nunca olvidaré

17 Ibid., p. 100, nota al verso 1416. El comentario de Herrera dice: "baxíssimo i torpe verso en numero i sentencia. Esto no sé como lo dixo Garci-Lasso, que mui ageno es de su modestia i pureza; porque deslustró mucho la limpieza i onestidad de toda esta descrición. Cosiste la onestidad de los vocablos ó en el sonido ó en la voz d'ellos ó en su significado que nobres ai que dizen cosa onesta i se siente resonar desonestidad en la misma voz; pero la ocenidad i torpeza no sólo no a de estar en las palabras, mas ni en la significación, porque siempre se a de cubrir en la oración la torpeza de las cosas; i si se cubre, como se entienda, satisfaze i agrada." Garcilaso de la Vega. Las Eglogas con las anotaciones de Herrera (Paris: Librería de la Vda. de Ch. Bouret, 1939), pp. 219-20. Lo interesante aquí, por supuesto, no es la censura moral de Herrera, sino la correspondencia que establece entre torpeza moral y poética. Elias L. Rivers estudia la presencia del mito de Narciso en la Egloga II, y dice: "The soul's mistaken pursuit of the body is thus a frustrating error, for only a beauty at its own, or a higher level can satisfy the soul. This is precisely the division between soul and body which Albanio imagines as, in his madness, he looks at his reflection in the water; and the results are similarly frustrating. It is the carnal nature of Albanio's love for Camila which Nemoroso says must be cured by Severo's Platonic lessons concerning the true nature of the soul (vv. 1094 and 1127: 'y restituye'l alma a su natura,' 'Que volvió el alma a su naturaleza'). Unlike the Ovide moralisé tradition, which condemned Narcissus as representing willfully conceited self-love, the Neoplatónic tradition sees him as inadequate self-knowledge, substituting for the soul its inferior reflection, or hypostasis, the body, as the object of true love." Hispanic Review, 41 (1973), p. 303. En el poema, desde luego, no pueden aislarse tan nítidamente esas tradiciones, sino que por el contrario queda la torpeza que emerge del enfrentamiento entre lo concreto carnal y la idea de belleza.

18 Obras, op. cit., p. 46. 
aquel relicario de una iglesia granadina que llena una sala entera; que con el brillo del oro, del cristal y la luz eléctrica, parece el vestuario de una elegante cortesana. Mientras que en cada cajita se encuentran huesos y otros restos de santos. [...] A esa belleza de nimbos pertenece el oropel del lenguaje culterano y conceptista, cuyas "pseudopalabras" el mismo poeta conoce muy bien, por eso puede muy bien escribir en barroco. O lo que es lo mismo, hacer que sus personajes hablen en barroco y que ellos mismos critiquen su lenguaje. El poeta conoce lo oportuno y al mismo tiempo lo inoportuno de estos embellecimientos. ${ }^{19}$

El lenguaje a que desemboca el petrarquismo es uno en que la búsqueda de fusión y la conciencia de la ruptura conduce a la asimilación de lenguajes diversos, desarmónicos, como ya se ha visto en la Egloga de Garcilaso. Es el lenguaje de la falta de plenitud y de la plenitud perseguida en la sobreabundancia y la superfluidad: que señala el vacio, la ausencia de voz centralizadora, como Albanio apunta a su cuerpo fuera de si--una figura rosada, demasiado hermosa para ser suya.

San Juan, como sugiere Lezama, es el polo opuesto de esta tendencia; o tal vez la vertiente complementaria. San Juan está muy conciente de la falla del lenguaje, de la imposibilidad de expresar la plenitud que persigue:

esta es la causa por que con figuras, comparaciones y semejanças, antes rebosan algo de lo que sienten y de la abundancia de el espíritu vierten secretos mysterios que con razones lo declaran. Las quales semejanças, no leydas con la sencillez de el espíritu de amor et intelligencia que ellas lleuan, antes parecen deslates que dichos puestos en razon, según es de uer en los diuinos Cantares de Salomón y en otros libros de la Escriptura diuina, donde, no pudiendo el Espíritu Sancto dar a entender la abundancia de su sentido por términos vulgares y usados, habla mysterios en estrañas figuras y semejanças. De donde se sigue que los sanctos doctores, aunque mucho dicen y más digan, nunca pueden acabar de declararlo por palabras, así como tampoco por palabras se puede ello decir; y assi, o que de ello se declara ordinariamente es lo menos que contiene en sí. (los subrayados son míos) ${ }^{20}$

El movimiento hacia la plenitud lleva, o a la repetición y acumulación de figuras, metáforas--a los dislates, a la locura--, o por la vertiente correlativa y opuesta al vacío, a la noche unánime que borra toda traza. Si por un lado tenemos la hartura, la plenitud nunca alcanzada, por otro encontramos la negación de todo apetito:

Llamamos aquí noche a la privación del gusto en el apetito de todas las cosas, porque así como la noche no es otra cosa sino la privación de la luz y, por consiguiente, de todos los objetos que se pueden ver mediante la luz, por lo cual se queda la potencia visiva a escuras y sin nada, así también se puede decir la mor-

19 Die Literarisierung des Lebens in Lopes Dorotea (Bonn y Koln: Ludwing Röhrscheid Verlang, 1932), pp. 1112. Agradezco a mi colega de Cornell, Ciriaco Morón Arroyo, su asistencia en la traducción de este pasaje.

zo "Prólogo" al "Cántico espiritual," Vida y obras de San Juan de la Cruz (Madrid: Biblioteca de Autores Cristianos, 1964), p. 740. 
tificación del apetito noche para el alma, porque privándose el alma del gusto del apetito en todas las cosas, es quedarse como a escuras y sin nada. Porque, así como la potencia visiva mediante la luz se ceba y apacienta de los objetos que se pueden ver, y apagada la luz no se ven, así el alma mediante el apetito se apacienta y ceba de todas las cosas que según sus potencias se pueden gustar, el cual también apagado, o por mejor decir, mortificado, deja el alma de apacentarse en el gusto de todas las cosas, y así queda según el apetito a escuras y sin nada. ${ }^{21}$

La lisura del verso de San Juan, la ausencia de adjetivos, la reducción del lenguaje a verbos y sustantivos, y a veces sólo a interjecciones, es la otra cara de la heterogeneidad barroca; el silencio sideral en la indiferenciada transparencia azul/el chisporroteo de la luz solar lanzada al infinito, asimilando la algarabia de astros y constelaciones: la afasia de Albanio, momentos después de su locura incoherente; ambos tiempos de un mismo movimiento hacia la recuperación de la voz poética--negativo en San Juan, asimilativo en el barroco. La página en blanco, la página negra, saturada de signos: contrapunteo de silencios.

El peregrino en las Soledades--ese "náufrago y desdeñado, sobre ausente" 22 ... deambula por el opulento paisaje que lo rodea, excluido. Como atinadamente señaló Pedro Salinas, su historia es un pretexto, el argumento del poema prácticamente nulo. ${ }^{23}$ ¿Qué sabe el lector del peregrino? Que es un náufrago en un país extraño ("el mísero extranjero," p. 645, v. 44), que sufre una pena de amor, y que como sus antecesores en las églogas, aparece aislado (aquí en el sentido etimológico), desarraigado: "Las Soledades tal como las tenemos--dice Dámaso Alonso--son más bien una sucesión de escenas pastoriles, con un largo relato histórico, unas bodas rurales, escenas de pesca, de cetrería, unidas sólo, como un hilo contínuo, por la presencia de ese peregrino solitario al que aflige una tremenda desaventura amorosa." 24 El peregrino es un espectador pasivo cuya historia se diluye en las complejas y minuciosas descripciones del contexto, de las propiedades de la brújula, de los descubrimientos maritimos, de todo, en fin--las anunciadas cuatro soledades iban a ser un poema cósmico, total. Las Soledades, que significativamente nunca fueron terminadas, aspiraban a ser, pues, un poema que lo contuviese todo; una especie de summa poética en la que todo fuese nombrado, y que agotase el registro de posibilidades metafóricas del lenguaje.

La ruptura que se ha venido observando en la tradición petrarquista llega en el poema de Góngora a su más aguda manifestación. El lenguaje recargado, retorcido, no es un lenguaje que denote una presencia, sino un lenguaje que busca la plenitud en sí mismo--el peregrino no puede ser sino pre-texto, o con-texto. Aislado como aparece en esa isla desconocida--rodeado por "el húmido templo de Neptuno"' (v. 478) --, el peregrino proyecta la imagen perfecta de la alienación. En su Histoire de la folie à l'age classique,

21 Subida al Monte Carmelo, op. cit., p. 369.

22 Góngora, Obras completas (Madrid: Aguilar, 1962), p. 634.

23 "The narrative part, the story is nothing but a slight pretext. Góngora makes use of it in order to indulge in descriptions of nature, plants, animals, landscape, in order to present dances, festivities, activities like hunting and fishing all of the greatest variety...' Reality and the Poet in Spanisb Poetry, intr. Jorge Guillen (Baltimore: Johns Hopkins University Press, 1966), p. 138.

24 Góngora y el "Polifemo", I, 4ta. ed. (Madrid: Gredos, 1961), p. 115. 
Michel Foucault ha consignado la relación entre la navegación y la locura, en términos que parecen de singular pertinencia al peregrino de las Soledades:

E1 [loco] es el Pasajero por excelencia, es decir el prisionero del pasaje. Y la tierra sobre la cual él desembarcará es desconocida, así como no se sabe, cuando pone pie a tierra, de dónde viene. El no posee su verdad ni su patria sino en esa extensión infecunda entre dos tierras que no pueủen pertenecerle. Será este ritual el que está por sus valores en los orígenes de un largo parentesco imaginario que puede seguirse por toda la historia de la cultura occidental? ¿O es que, a la inversa, este parentesco es el que ha convocado y fijado, desde lo más profundo del tiempo, el ritual del embarque? Una cosa por lo menos es segura: el agua y la locura han estado ligadas por mucho tiempo en los sueños del hombre occidental. ${ }^{25}$

El peregrino de Góngora es, pues, en el conocido neologismo de Joyce para pasajero, el pasencore-un ser incompleto que surge de las aguas de un mar que si bien no será barroco en sí, parece serlo en su dimensión metafórica.

Al referirse al barroco, Lezama acude a veces, en forma metafórica, al concepto aristotélico-escolástico del húmedo radical, a aquella propiedad de los cuerpos que les da elasticidad y les permite la absorción del mundo externo. Y en "La curiosidad barroca", Lezama ofrece una especie de antología poético-culinaria que presenta con las siguientes palabras: "El banquete literario, la prolífica descripción de frutas y mariscos, es de jubilosa raíz barroca. Intentemos reconstruir, con platerescos asistentes de uno y otro mundo, una de esas fiestas regidas por el afán, tan dionisíaco como dialéctico, de incorporar el mundo, de hacer suyo el mundo exterior, a través del horno transmutativo de la asimilación.", 26 Y en Paradiso, como ha notado Emir Rodríguez Monegal, "el ritual de la comida desde su preparación hasta su exégesis práctica, ocupa un lugar absolutamente central." 27 Reveladora es, además, la imagen utilizada por Lezama en el notorio capítulo 8 de esa novela, al describir el coito per angostam viam de Farraluque y la criada del colegio: "Pero la españolita, con una tenacidad de ceramista clásico, que con sólo dos dedos le abre toda la boca a la jarra, llegó a unir las 'dos fibrillas de los contrarios, reconciliados en aquellas profundidades." ${ }^{28}$ Conviene recordar aquí que Santo Tomás, fiel a Aristóteles, aceptaba la teoría de que la creación de una mujer podía ser precipitada por causas externas, como por ejemplo, el viento sur, que es húmedo (Summa, p. 92, art. 1), y por lo tanto la creencia de que el cuerpo femenino contiene más agua que el masculino--de donde se deduce que es más elástico, como la arcilla de que fue moldeado. El barroco, pues, es el apetito incorporador, la asimilación. La insuficiencia o "incompletez" que Lezama le atribuye a Góngora es un apetito: "Todo vivir en el reino de la poesía in extremis--dice Lezama--, aporta la configuración del vivir de salvación, paradojal, hiperbólico, en el reino. Así, don Luis, estático, ocioso, indolente, lejano y litúrgico, fue el creador de un vivir de

26 La curiosidad barroca, op. cit., p. 58.

27 "Paradiso en su contexto," Mundo Nuevo, 24 (1968), p. 41.

28 Paradiso (Buenos Aires: Ediciones de la Flor, 1968). 
apetito o impulsión de metamorfosis." ${ }^{29}$ Para Lezama, Góngora ha llevado la poesía hasta el punto en que ésta quiere dejar de ser imagen del mundo para incorporar al mundo: mundo-palabra, sustanciación de la imagen en la poesía. La locura, la "incompletez" de Góngora está en que el apetito ha de ser siempre infinito y circular--serpiente que se devora y hace desaparecer, que se anilla y anula. Como la serie infinita de números del 1 al 3 de que hablaba Spengler, las posibilidades combinatorias del lenguaje poético gongorino son interminables: "En Góngora--explica Lezama--esa raíz juglaresca hermética tiene vastísima tradición soterrada, sólo que a veces el rayo lanzado como una cometa por el juglar se devora en su propia parábola, sin alcanzar ese oscuro cuerpo oracular, pues las señales del señor de Delfos surgen en un pizarrón nocturno que tiende afanosamente a borrarlas." 30

El apetito de Góngora no es tan voraz como el de Lezama, ya que éste quiere convertir la absorción en sacramento, en unión trascendente: "Cuando ese dualismo sea vencido, volviéndose a sumergir en ese infuso espejeante, en que el propio sentido del vivir adquiera una forma más sacramental, un misterio conocido al tocar la carne del hombre, volverá a presentarse la necesidad poética como un alimento que rebasa la voracidad cognoscente y de gratuidad en el cuerpo.' ${ }^{3 i}$ Quizás la clave para entender la empresa de Lezama, sobre todo en Paradiso, no esté en Góngora, sino en Quevedo, en esa escena grotesca y sacramental del Buscón en que se sugiere que don Pablos está a punto de comer unos pasteles hechos de la carne de su padre ajusticiado y descuartizado. Hacia esa fusión se dirige José CemíCemí, que yo me inclino a ver, a pesar de la ortografia, como derivado o síntesis de sema, signo, y soma, cuerpo--. Como el peregrino de las Soledades, como Orlando y Albanio, Cemí es un ser incompleto, testigo, espectador, o perplejo partícipe de una difusa historia. Pero la escena final de Paradiso evoca el momento de la misa en que el sacerdote ingiere la hostia y el acólito suena la campanilla: " Un negro, uniformado de blanco, iba recogiendo con su pala las colillas y el polvo rendido. Apoyó la pala en la pared y se sentó en la cafetería. Saboreaba su café con leche, con unas tostadas humeantes. Comenzó a golpear con la cucharita el vaso, agitando su contenido. . Impulsado por el tintineo, Cemí corporizó de nuevo a Oppiano Licario. Las sílabas que oía eran más lentas. Era la misma voz, pero modulada en otro registro. Volvía a oír de nuevo: ritmo hesicástico, podemos empezar." 32 La voz modulada en otro registro es la del padre ausente, recuperada por mediación del poema de Licario, testigo presencial de la muerte del Coronel en Pensacola. Ahora podemos empezar, no volvemos a empezar; el texto leido no es sino la vía a ese momento de unión desde el cual se puede postular el texto perfecto, trascendental, después de la unión transmutativa. Al referirse a las catedrales góticas, Worringer hablaba de "trascendentalismo petrificado." Lezama aspira en su obra al milagro--a la encarnación del verbo: "La poesía se hace visible, hipostasiada, en las eras imaginarias, donde se vive

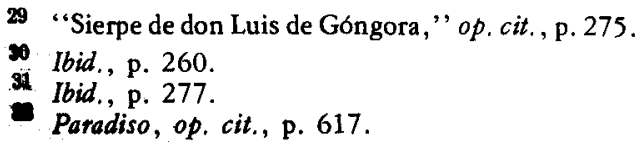


en imagen por anticipación en el espejo, la sustancia de la resurrección." 33

Cornell University

ROBERTO GONZALEZ ECHEVARRIA

33 Las eras imaginarias, op, cit., p. 30. Lezama recupera a Narciso (ver nota 17) al sacramentalizar la hipóstasis renacentista-barroca. Era esta caracteristica del barroco hispánico lo que atraía a Spitzer y a sus colegas alemanes, según indica en su ensayo "Il Barocco Spagnolo" : "Paganesimo, sí, puồ essere, ma paganessimo cristianizzato, che estrae spiritualità dalla carne voluttuosa, che mette al servizio di Dio la came stessa: la Spagna ha datto veramente carne alla seconda persona della Trinitã, al verbo caro factum." Cinque Saggi de Ispanistica, presentazione e contibuto bibliografico a cura di Giovanni Maria Bertini. Collaborazione di Roberto Radicadi di Marmorito (Turín: G. Giappichelli, 1962), p. 117. 
